\title{
Mit Aktivsauerstoff den Bakterien auf der Spur!
}

Die miradent Miraclin Implant Zahncreme wurde speziell für die Bedürfnisse von Implantat-Zahnersatz entwickelt und bietet einen optimalen Rundum-Schutz für Implantate und Zähne. Gleichzeitig bewahrt die aktive Sauerstofftechnologie das natürliche Weiß der Zähne und verhindert die Bildung von Farbunterschieden zwischen natürlichen und implantierten Zähnen. Selbstverständlich kann das Produkt auch bei natürlichen Zähnen verwendet werden. Das Schutz-Enzym Lactoferrin unterstützt die Regeneration beschädigter Zellen und reduziert die Bildung entzündungsfördernder Bakterien auch an den Stellen, an die die Zahnbürste nicht hingelangt. Die Paste ist pH-neutral und hat einen Fluoridanteil von 200 ppm im Vergleich zu den handelsüblichen 1450 ppm. Hierdurch reduziert man die Korrosion von Implantaten durch die Flu- oride und profitiert dennoch von den wichtigen remineralisierenden Eigenschaften.

Nach einer Pressemitteilung der

Hager \& Werken GmbH \& Co. KG, Duisburg

www.hagerwerken.de

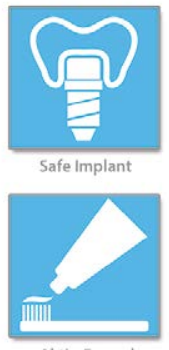

Aktiv-Forme

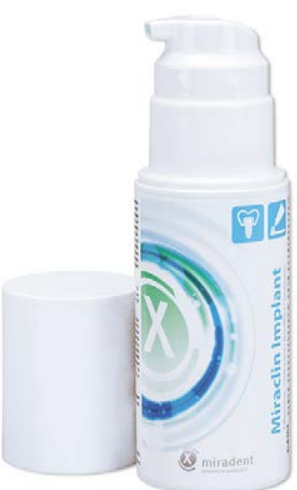

